\title{
Two-phase flow patterns in adiabatic refrigerant flow through capillary tubes
}

\author{
Luka Lorbek*, Anja Kuhelj, Matevž Dular, Andrej Kitanovski \\ Laboratory for Refrigeration and District Energy, University of Ljubljana, Faculty of Mechanical Engineering, Ljubljana, Slovenia
}

\section{A R T I C L E I N F O}

\section{Article history:}

Received 21 October 2019

Revised 17 February 2020

Accepted 18 February 2020

Available online 1 March 2020

\section{Keywords:}

Vapor-compression system

Refrigerant flow

Capillary tube

Flash evaporation

Flow visualization

\begin{abstract}
A B S T R A C T
This paper presents the results of an experimental study of the flow visualization of the refrigerant R600a through a capillary tube with an internal diameter of $0.8 \mathrm{~mm}$ made from a FEP (fluorinated ethylene propylene) polymer that was installed in a small-scale, vapor-compression refrigeration system. The main purpose of the study was to determine the flow patterns of the refrigerant flow in capillary tubes under different operating conditions and to verify whether the results obtained using a FEP tube are representative for the flow of a refrigerant in copper capillary tubes. The results of the study revealed that the two-phase refrigerant flow in the FEP capillary tubes consists predominantly of slug flow. These slugs continuously expand while traveling downstream. It was also found that different operating conditions can have a strong influence on the frequency of the vapor bubbles' formation and their growth. In addition, an experimental study of the effect of local or global imperfections on the inner surface of the FEP tube was performed. In some cases the imperfections increased the number of vapor-bubble inception points, which caused a homogenization of the two-phase flow.
\end{abstract}

(c) 2020 Elsevier Ltd and IIR. All rights reserved.

\section{Configurations d'écoulement diphasique pour un écoulement de frigorigène adiabatique à travers des tubes capillaires}

Mots clés: Système à compression de vapeur; Écoulement de frigorigène; Tube capillaire; Évaporation instantanée; Visualisation de l'écoulement

\section{Introduction}

Refrigerant flow in capillary tubes has attracted the interest of many researchers due to its complexity and its effect on the overall performance of vapor-compression refrigeration systems. Many experimental studies describing the properties of refrigerant flow in both adiabatic or non-adiabatic capillary tubes can be found in works such as Pate and Tree (1984), Lin et al. (1991), Dirik et al. (1994), Bittle et al. (1995), Melo etal. (1999), Melo et al. (2002), and da Silva et al. (2011), and in reviews such as Schulz (1985), Khan et al. (2009), Dubba and Kumar (2017). Unlike electronic expansion valves (EEVs) capillary tubes have no moving parts and are very simple in terms of design. This makes them inexpensive compared to EEVs (Arora, 2009). The downside is that

\footnotetext{
* Corresponding author.

E-mail address: luka.lorbek@fs.uni-lj.si (L. Lorbek).
}

they are not able to actively regulate the flow of the refrigerant to the evaporator and therefore cannot adjust to varying load conditions (Melo et al., 1999). They are commonly used in smaller vapor-compression systems such as household refrigerators, where the operating conditions do not change significantly. In such cases the capillary tubes can perform as well as EEVs (Marcinichen and Melo, 2006). In a refrigeration system their purpose is to decrease the pressure of the condensed refrigerant below the saturation pressure. At this point the refrigerant will start to evaporate and expand. Consequently, its temperature will decrease. This lowtemperature refrigerant, whose mass flow rate is controlled by the capillary tube, will then flow to the evaporator where it can absorb the heat from the thermal source. The pressure drop in a capillary tube is the result of the large friction forces acting on the fluid due to the small diameter and thus a higher relative roughness. It is also caused by the continuous acceleration of the fluid due to a decreasing density caused by the gradual increase of the vapor 


\begin{tabular}{|c|c|}
\hline \multicolumn{2}{|c|}{ Nomenclature } \\
\hline \multicolumn{2}{|c|}{ Symbols } \\
\hline A & tube cross-section $\left[\mathrm{m}^{2}\right]$ \\
\hline G & mass flow rate $\left[\mathrm{kg} \mathrm{s}^{-1}\right]$ \\
\hline $\mathrm{p}$ & pressure [Pa] \\
\hline $\mathrm{x}$ & coordinate axis [m] \\
\hline $\mathrm{t}$ & time $[\mathrm{s}]$ \\
\hline $\mathrm{v}$ & velocity $\left[\mathrm{m} \mathrm{s}^{-1}\right]$ \\
\hline \multicolumn{2}{|c|}{ Greek letters } \\
\hline$\rho$ & density $\left[\mathrm{kg} \mathrm{m}^{-3}\right]$ \\
\hline \multicolumn{2}{|c|}{ Subscripts } \\
\hline $\mathrm{L}$ & liquid \\
\hline EEV & electronic expansion valve \\
\hline FEP & fluorinated ethylene propylene \\
\hline FPS & frames per second \\
\hline ID & internal diameter \\
\hline OD & outer diameter \\
\hline PID & proportional integral derivative \\
\hline RPM & revolutions per minute \\
\hline RTD & resistance temperature detector \\
\hline
\end{tabular}

fraction. This process of adiabatic evaporation is a very complex phenomenon. It involves turbulent, two-phase, phase-changing, compressible flow. A delay in vaporization, called the metastable flow, can also occur (Pascua, 1953; Cooper et al., 1957; Li et al., 1990). To better understand the two-phase flow in capillary tubes several researchers have performed different refrigerantflow visualization studies. Cooper et al. (1957) were among the first to describe the two-phase refrigerant flow as a "fog flow" while studying the delay of vaporization in glass capillary tubes. In their study Mikol and Dudley (1964) used a stroboscope in order to visualize the flow of R12 in a glass capillary tube. Their results showed an intense bubbly flow and sometimes an annular flow that formed a vapor core surrounded by liquid. Near the outlet of the capillary tube the flow was described as a "uniform spray of liquid droplets borne by vapor". Koizumi and Yokoyama (1980) performed an investigation of the flow of the R22 refrigerant through a capillary tube made of Pyrex glass with an inner diameter of $1.0 \mathrm{~mm}$. At the point of inception, the bubbles were seen to grow and combine, whereas at the outlet of the capillary tube the flow was described as a "homogeneous" bubbly flow. By visualizing the refrigerant flow of R404A Motta et al. (2002) studied whether the concentration of the compressor oil has an effect on the delay of vaporization in a capillary tube. By changing the oil concentration, they managed to influence the vaporization point. They described the flow as a fog-like flow. Vinš et al. (2010) studying R218 reported that non-condensable gases trapped in the system can cause an earlier onset of vaporization resulting in a smaller mass flow rate through the capillary tube. In this case the shift in vaporization was observed through pressure measurements not visualization. Martinez-Ballester et al. (2017) performed a visualization of the flow of R600a at the inlet of the capillary tube in a household refrigerator. They showed that despite the refrigerant being in a subcooled state vapor was still present and was being continuously drawn into the capillary tube along with the liquid. Similar observations were made by Hartmann and Melo (2013) who correlated the so-called popping noise in household refrigerators and the entrainment of vapor bubbles at the capillary tube's inlet. After the initial studies in the 1950s and $60 \mathrm{~s}$, little attention was given to the visualization of refrigerant flow in capillary tubes. As such the flow of refrigerant through capillary tubes has been commonly viewed as a homogenous bubbly/misty flow, especially in studies related to the mathematical modeling of the refrigerant flow (Sami and Maltais, 2000; Xu and Bansal, 2002; Bansal and Rupasinghe, 1998; Bullard and Jain, 2004; Heimel et al., 2012; Wongwises and Pirompak, 2001; Agrawal and Bhattacharyya, 2007). Due to advances in photographic and lighting technologies Tannert and Hesse (2016) noticed different flow patterns, such as plug flow at the capillary tube's outlet, while examining the noise effects caused by refrigerant flow in the capillary tube of a household refrigerator. Such a flow pattern indicates the presence of a heterogeneous flow. A number of mathematical models of capillary tubes (Garcia-Valladares, 2007; Wang et al., 2012; Seixlack and Barbazelli, 2009; Seixlack, 1996) that are based on the separated two-phase flow model where the flow is assumed to be heterogeneous can be found in the literature. The results reported in these studies agree slightly better with the experimental results compared to homogeneous models, but several studies (Furlong and Schmidt, 2012; Wong and Ooi, 1996) point out that both two-phase models can be used to describe the flow of refrigerants in capillary tubes. Although homogeneous and separated flow models have been compared extensively with each other and against experimental data, no investigation, at least to the best of the authors' knowledge, has been made to experimentally determine the velocity ratio of the vapor and liquid phases, which is one of the key parameters that indicate the homogeneity of the flow. Therefore, we decided to investigate the flow of R600a through a capillary tube installed in a small-scale, vapor-compression refrigeration system. The primary goal was to observe the flow patterns in the two-phase region of the capillary tube flow from which an attempt would be made to determine the velocity ratio. Because the capillary tube that was used to enable the visualization of the flow was made from a FEP polymer the second part of the study focused on the effects of two different surface-texture properties. The goal was to try and determine whether, or to what extent, the flow patterns in a FEP capillary tube are representative of the flow in a copper capillary tube that is actually used in vapor-compression systems.

\section{Experimental set-up}

To ensure similar flow conditions to those in real applications and to be able to control and regulate them, an experimental vapor-compression refrigeration system was set up. The system was designed to mimic the operation of a real household refrigerator, charged with the refrigerant R600a. No oil-separator was installed, as is the case for most household refrigerators. This means that the working fluid was an oil-refrigerant mixture. However, the effects of the oil's presence were not studied. The evacuation and filling procedures were carried out meticulously to ensure as little air as possible would enter the system because non-condensable gases can have an effect on the onset of vaporization in a capillary tube (Vinš et al., 2010). A scheme of the set-up is shown in Fig. 1.

The refrigeration system comprises a variable-speed piston compressor connected to a Coriolis mass-flow meter and a dynamic condenser. A sight glass and a filter drier are positioned after the condenser. Connected to these is the test section for capillary tubes that enables the simultaneous installation of up to two capillary tubes. The capillary tube is inserted into a Plexiglass tube that makes it possible to visualize the flow at the outlet. A static evaporator is located inside an insulated cabinet. Pressure and temperature measurements are taken at the inlet and outlet of each main component. Two electric heaters control the air temperature in the cabinet via a PID (proportional-integral-derivative) controller connected with an RTD (resistance temperature detector). The PID controller is also connected with one pressure sensor on the condensing side and one on the evaporating side. The 


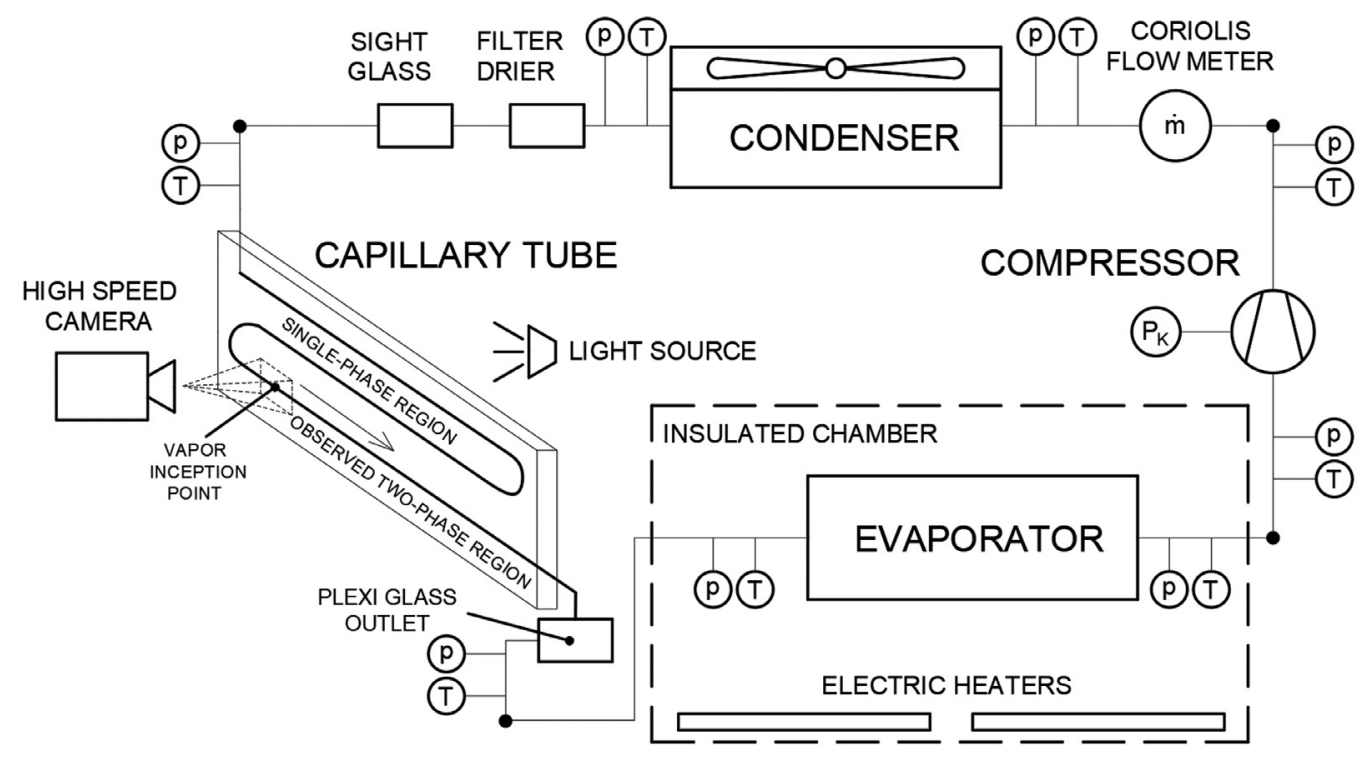

Fig. 1. Schematic of the experimental set-up.

Table 1

Measuring equipment and features.

\begin{tabular}{lll}
\hline & Type/Range & Accuracy \\
\hline Pressure transmitters & Pressure transmitter $0 \ldots 25$ bar (absolute) & $\pm 0.3 \%$ of measurement range $( \pm 0.08$ bar $)$ \\
& Pressure transmitter $-1 \ldots 12$ bar (relative) & $\pm 0.3 \%$ of measurement range $( \pm 0.04$ bar) \\
Thermocouples & K-type & $\pm 0.2 \mathrm{~K}($ calibrated $)$ \\
Coriolis mass flow meter & $0 \ldots 90 \mathrm{~kg} \mathrm{~h}^{-1}$ & $>4 \mathrm{~kg} \mathrm{~h}^{-1} \ldots<0.5 \%$ \\
& & of measured value \\
& & $<4 \mathrm{~kg} \mathrm{~h}^{-1} \ldots<1.5 \%$ \\
& & of measured value \\
High-speed camera & Properties & \\
& 1.3 Megapixels & \\
& $1280 \times 1024$ resolution at $2000 \mathrm{FPS}$ & \\
& Flow observed at 20000 and $32000 \mathrm{FPS}(1280 \times 152)$ & \\
\hline
\end{tabular}

pressure and temperature at the inlet of the capillary tube are regulated by varying the condenser fan's rotation. By increasing the rotational speed of the fan, heat transfer from the condenser to the surroundings increases. Consequently, the condensing (capillary inlet) pressure and temperature will decrease. The pressure at the outlet of the capillary tube is independent of the downstream conditions if the flow at the outlet is choked. If the flow is not choked, the pressure at the outlet of the capillary tube (the evaporating pressure) can be regulated by increasing or decreasing the compressors' RPM. Higher compressor rotation speeds cause a higher mass flow rate, which will in turn increase the pressure drop through the capillary tube. If the inlet pressure is held constant the evaporating pressure will decrease. The refrigerant flow in the capillary tube was observed with a high-speed camera. The camera was positioned parallel to the capillary tube, which was attached to a Plexiglass plate. An LED was placed behind the glass plate to illuminate the flow. Because we wanted to observe the refrigerant flow along the entire length of the capillary tube, which can be up to a few meters, it was unpractical to make the capillary tube from glass. Therefore, a transparent FEP polymer tube with an internal diameter of $0.8 \mathrm{~mm}$, an external diameter of $1.6 \mathrm{~mm}$ and a length of $3.1 \mathrm{~m}$ was selected as our capillary tube. FEP is a polymer commonly used in capillary electrophoresis and has a high inertness towards most chemicals (Sahlin, 2002). This property is important because the refrigerant must not dissolve the polymer. Otherwise the refrigerant could become contaminated or could eventually damage the wall of the capillary tube. For this reason, preliminary tests were carried out on the effect of the exposure of the polymer to the refrigerant. The refrigerant was in contact with the polymer for three weeks and the tube did not show any noticeable signs of reaction or change. As the mass flow rate was measured after the compressor all the measurements were performed after the system reached a steady state, when the mass flow rates through the capillary tube and the compressor were equalized. Table 1 contains the information about the measuring equipment that was used in the experiment.

\section{Results and discussion}

\subsection{Performance comparison of the FEP and the copper capillary tube}

Whereas most researchers who performed visual studies utilized glass capillary tubes, in our study the capillary tube was made of fluorinated ethylene propylene (FEP). Since the flow behavior with respect to the transparent FEP and copper tubes could differ, the first step in the experimental analysis was to evaluate the operating conditions for the same geometry of both capillary tubes in a vapor-compression system. For the purpose of the study, a FEP and a copper capillary tube with an internal diameter of $0.8 \mathrm{~mm}$ (information provided by the manufacturers) and a length of $2 \mathrm{~m}$ were installed in the experimental set-up. The mass flow rate and pressure drop were measured for different compressor RPM ranging from $30 \%$ to $100 \%$ of the nominal value. The difference in the mass flow rate at which the system reaches steadystate conditions between the FEP and copper capillary tubes is within the measurement uncertainty when increasing the compressor RPM. A difference of around 5\% can be noticed only when the flow approaches choked conditions. In this case for the same 


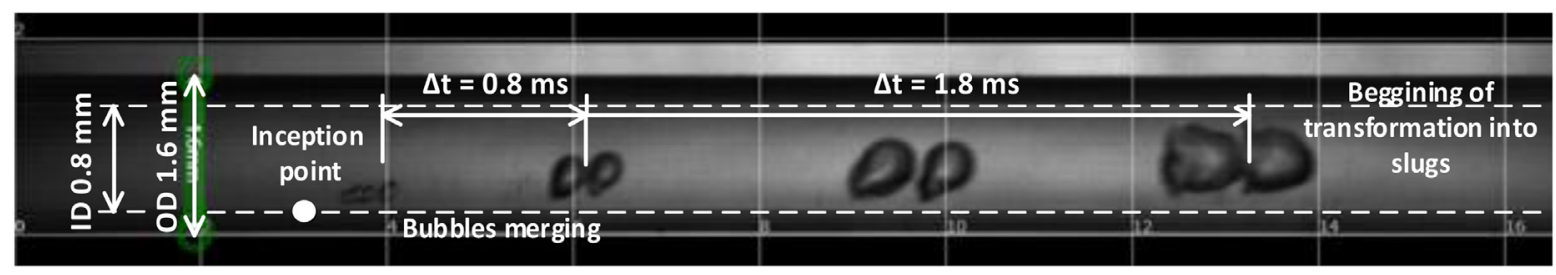

Fig. 2. Vapor slug formation at inlet pressure of $6.1 \mathrm{bar}$, inlet temperature $35^{\circ} \mathrm{C}$ and mass flow rate of $2.5 \mathrm{~kg} \mathrm{~h}-1$.

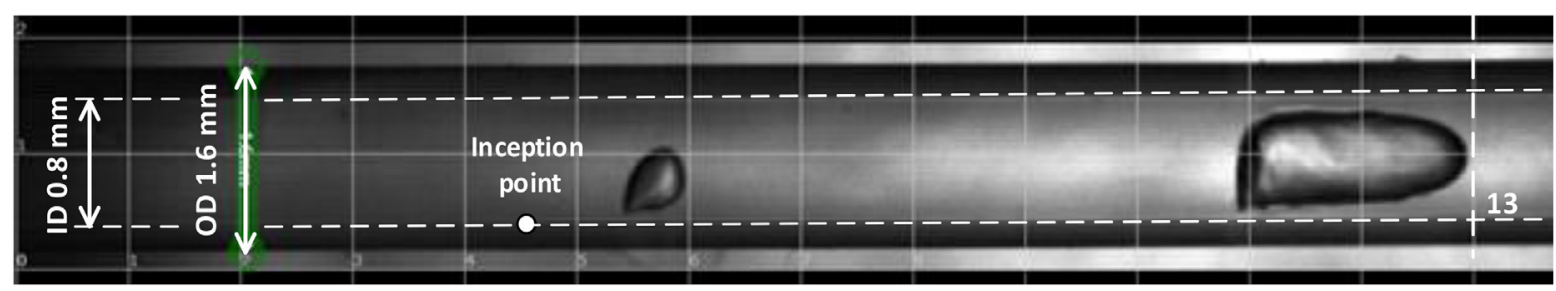

Fig. 3. Vapor slug formation at inlet pressure of $4.7 \mathrm{bar}$, inlet temperature $28.1^{\circ} \mathrm{C}$ and mass flow rate of $2.2 \mathrm{~kg} \mathrm{~h}^{-1}$.

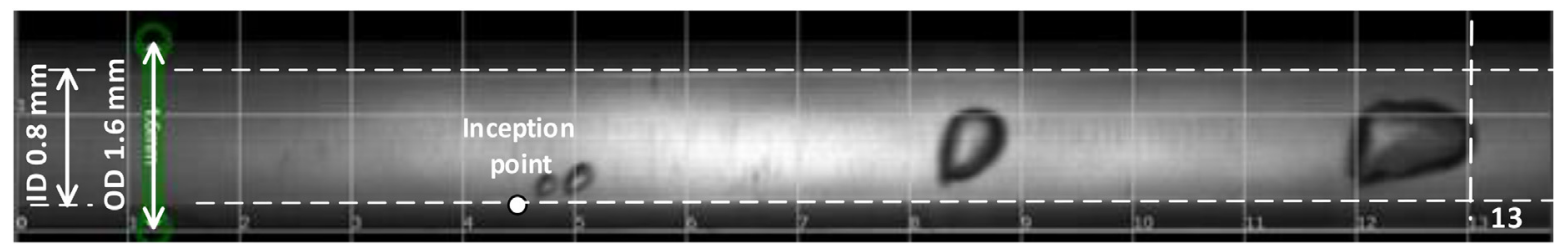

Fig. 4. Vapor slug formation at inlet pressure of 5.3 bar, inlet temperature $31.7^{\circ} \mathrm{C}$ and mass flow rate of $2.4 \mathrm{~kg} \mathrm{~h}{ }^{-1}$.

inlet conditions the FEP capillary tube can provide a slightly larger mass flow rate than the copper tube. Likewise, the pressure drop did not vary by more than $\pm 3 \%$ at different mass flow rates. The refrigerant charge and the inlet pressure were equal in both test cases. At low compressor RPM the subcooling degree varied by a maximum of $0.7 \mathrm{~K}$ or around $18 \%$ of the absolute subcooling degree. This was due to the lack of a mechanism that could regulate a constant subcooling. The result shows that in terms of pressure drop, which is an indicator of the surface roughness, the FEP capillary tube has similar properties to a copper capillary tube. However, it must be pointed out that the difference in the pressure drop and mass flow rate could also be the result of a slightly different internal diameter and not only a different surface roughness.

\subsection{Inception of vaporization}

In their research on glass capillary tubes Mikol and Dudley (1964) reported that the inception of vaporization always occurred at one point on the tube wall, never around the entire circumference and never in the entire cross-section of the flow. This agrees with our observations. The vaporization always occurred at a single point on the lower part of the tube wall. We emphasize that even though the vaporization point did not change, the absolute values on the gridlines of different figures can be different as the camera was moved around during the different shots. Fig. 2 shows an example of the bubble formation at the inception point. The scale on the figure marks the outer diameter and the dotted lines indicate the tube's interior. The outer diameter was chosen as the scale because we were unsure of the effects that light refraction might have on the scale of the internal diameter. The white circle indicates the inception point. Small bubbles rise from the surface of the tube in groups of 1 to 4 bubbles, depending on the operating conditions. They then quickly merge into larger bubbles that are carried downstream by the liquid refrigerant. This is followed by a pause when no evaporation occurs. The bubbles that are being carried downstream begin to expand in the direction of the flow. This is probably because the pressure downstream is lower than the pressure upstream. Therefore, its growth is less restricted in the direction of the flow. The bubbles also begin to accelerate and transform into slugs.

Fig. 3- depict the inception of vapor bubbles and their transformation into slugs for two more operating conditions where the mass flow rate was varied from $2.2 \mathrm{~kg} \mathrm{~h}^{-1}$ to $2.4 \mathrm{~kg} \mathrm{~h}^{-1}$. The inlet pressure was varied from 4.7 bar to 5.3 bar and the inlet temperature was varied from $28.1^{\circ} \mathrm{C}$ to $31.7^{\circ} \mathrm{C}$.

We mentioned that the bubbles appear in groups (Figs. 2-4 each show one group at their respective flow conditions) followed by a pause when no evaporation occurs. The frequency at which these bubble bursts and other vapor formations downstream (see Section 3.3.) appear ranges from around $33 \mathrm{~Hz}$ in Fig. 3 to $46 \mathrm{~Hz}$ in Fig. 2. It remains more or less constant along the capillary tube's length even when downstream of the point of inception the small bubbles merge into a single slug. It is possible to assume that a constant frequency along the length of the capillary tube means that although the smaller bubbles from one group burst merge into a slug, the slugs from different groups do not manage to merge with each other as they are formed too far apart. The increase in the frequency of the bubble formation could perhaps be attributed to some effects caused by an increased liquid velocity at the point of inception. Table 2 shows these velocities and other flow properties for the cases in Figs. 2-4. The liquid velocity in the singlephase region was determined from Eq. (1)

$v=\frac{G}{\rho_{L} A}$

where $\mathrm{G}$ is the mass flow rate $\left[\mathrm{kg} \mathrm{h}^{-1}\right], \rho_{\mathrm{L}}$ is the liquid density [ $\mathrm{kg}$ $\left.\mathrm{m}^{-3}\right]$ and $A$ is the tube's cross-sectional area $\left[\mathrm{m}^{2}\right]$.

From Fig. 2- we can see that different operating conditions can affect the shape of the formed slugs, the frequency at which they appear, and their velocity. In Fig. 3 the single vapor bubble is already transformed into a slug at the $13-\mathrm{mm}$ grid mark, having expanded downstream as its rear was pushed on by the liquid. 
Table 2

Flow properties for the cases presented in Figs. 2-4.

\begin{tabular}{|c|c|c|c|c|c|c|c|}
\hline $\begin{array}{l}\text { Inlet } \\
\text { pressure } \\
\text { [bar] }\end{array}$ & $\begin{array}{l}\text { Mass flow } \\
\text { rate }\left[\mathrm{kg} \mathrm{h}^{-1}\right]\end{array}$ & $\begin{array}{l}\text { Inlet temperature } \\
{\left[{ }^{\circ} \mathrm{C}\right]}\end{array}$ & $\begin{array}{l}\text { Saturation } \\
\text { (flashing) } \\
\text { pressure [bar] }\end{array}$ & $\begin{array}{l}\text { Liquid velocity } \\
\text { before vaporization } \\
{\left[\mathrm{m} \mathrm{s}^{-1}\right]}\end{array}$ & $\begin{array}{l}\text { Vapor } \\
\text { velocity } \\
{\left[\mathrm{m} \mathrm{s}^{-1}\right]}\end{array}$ & $\begin{array}{l}\text { Frequency of } \\
\text { bubble group } \\
\text { formation }[\mathrm{Hz}]\end{array}$ & $\begin{array}{l}\text { Reynolds number } \\
\text { before } \\
\text { vaporization [/] }\end{array}$ \\
\hline 4.7 & 2.2 & 28.1 & 3.8 & 2.2 & 3.1 & 33 & 6580 \\
\hline 5.3 & 2.4 & 31.7 & 4.2 & 2.4 & 3.3 & 37 & 7370 \\
\hline 6.1 & 2.5 & 35.0 & 4.6 & 2.6 & 3.7 & 46 & 8080 \\
\hline
\end{tabular}

At this point, the shape of the slug resembles a so-called Taylor bubble (Taylor, 1960). In Fig. 2 bursts of smaller bubbles are still joining together into larger bubbles. This can perhaps be attributed to the pressure of the liquid phase surrounding the bubble, restricting its growth. As can be seen in Table 2 the liquid surrounding the bubbles in Fig. 2 has a higher pressure than the liquid in Figs. 3 and 4 as the saturation pressure is higher in this case. We can also see that the average velocity of the vapor phase increases from $3.1 \mathrm{~m} \mathrm{~s}^{-1}$ in Fig. 3 to $3.3 \mathrm{~m} \mathrm{~s}^{-1}$ in Fig. and to $3.7 \mathrm{~m}$ $\mathrm{s}^{-1}$ in Fig. 2 due to the increase of the mass flow rate. The vapor slugs have a shape that resembles the pattern of vertical slug flow in a tube (Weisman, 1983) even though the tube was faced horizontally. We believe that this is due to the high velocity of the flow and the small diameter of the tube.

\subsection{Flow patterns along the distance of the capillary tube}

The following figures (the reader is referred to the video stills) show an example of the two-phase flow patterns observed at discrete points along the capillary tube. We would like to emphasize that the flow was not recorded simultaneously at all points. The camera was moved from point to point and around 1-2 s of the flow was recorded at each location while the system was continuously operating. A coordinate axis $\mathrm{x}$ with a positive direction toward the capillary tube outlet was used to mark the different locations where the flow was observed. The outlet of the capillary tube is located at $x=50 \mathrm{~cm}$ and $x=0$ is a point $50 \mathrm{~cm}$ upstream from the outlet. The inlet pressure was set to $4.7 \mathrm{bar}$ and the mass flow rate through the capillary tube was $2.2 \mathrm{~kg} \mathrm{~h}^{-1}$. Fig. 5 shows the starting point of the vaporization. The bubbles form on the lower wall and begin expanding into a slug (see also Fig. 3).

The slug (underlined with a white line in Figs. 5 and 6) expands very quickly, increasing in size from $L=2 \mathrm{~mm}$ in Fig. $5(x=25.5 \mathrm{~cm})$, to $L=14 \mathrm{~mm}(x=28 \mathrm{~cm})$, as shown in Fig. 6 .

By $x=32 \mathrm{~cm}$ in Fig. 7 the slugs that formed from bubbles from the same bubble burst begin to merge with each other because their front-end velocities are much higher than their rear-end velocities. The difference in the velocity is shown later in Fig. 10.

After merging in Fig. 7 the slug shown in Fig. 8 (at $x=42 \mathrm{~cm}$ ) continues to expand and accelerate. However, it is now followed by a patch of mist. This misty patch is attached to the slug and seems to be formed of small vapor bubbles. The refrigerant vapor flows as this continuous slug until the outlet of the capillary tube. The slug in Fig. 8 is split into two parts because we were unable to fit the entire slug into one frame.

Most vapor-compression systems have their capillary tube inserted and soldered straight into the evaporator tube. We tried to recreate this geometry by inserting the capillary into a $15 \times 15 \mathrm{~mm}$ plexi-glass block with an internal tube of $5 \mathrm{~mm}$, as shown in Fig. 9. The contact between the tube and plexi-glass was minimized as much as possible to prevent heat transfer having a significant effect on the refrigerant flow. The flow at this location was hard to visualize, but from our observations we conclude that after the refrigerant flows out of the capillary tube the liquid phase is forced against the tube wall as the vapor core expands into the tube. When the misty rear end of the slug that is shown in Fig. 8 (bottom) exits the capillary it fills the tube with tiny bubbles for a brief moment before the vapor core again starts pressing the liquid against the tube wall.

In conclusion, it becomes clear that the evaporating process is very dynamic in nature. However, the dynamics of the evaporation happen on a timescale of just a few milliseconds. Due to this the flow might be considered as semi-steady on a larger timescale.

\subsection{Velocity of the vapor phase}

The velocity of the vapor phase is relatively simple to determine because the vapor patterns can be clearly seen and the distances that they travel in a certain period of time are clear. However, the liquid velocity cannot be determined visually because no visible patterns occur. In the single-phase region the liquid velocity can be determined with Eq. (1). In the two-phase

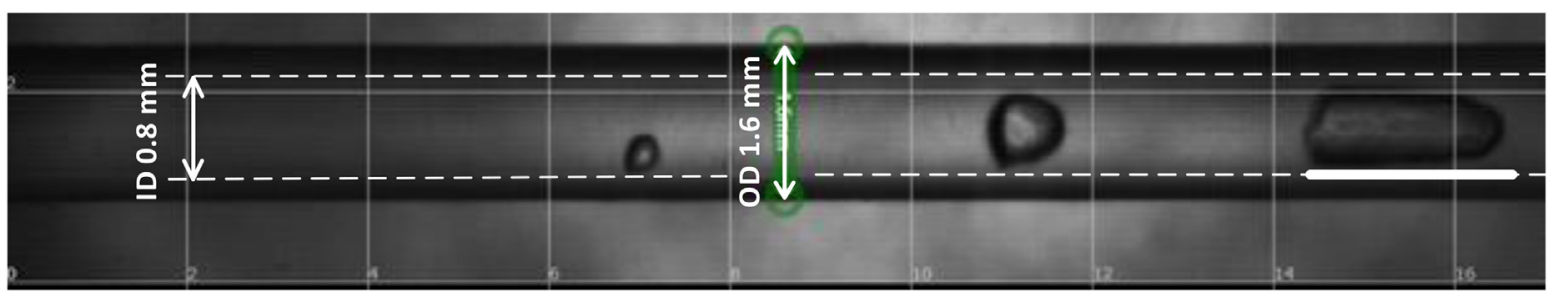

Fig. 5. Point of vapor inception. Bubbles begin forming into slugs $(x=25.5 \mathrm{~cm})$.

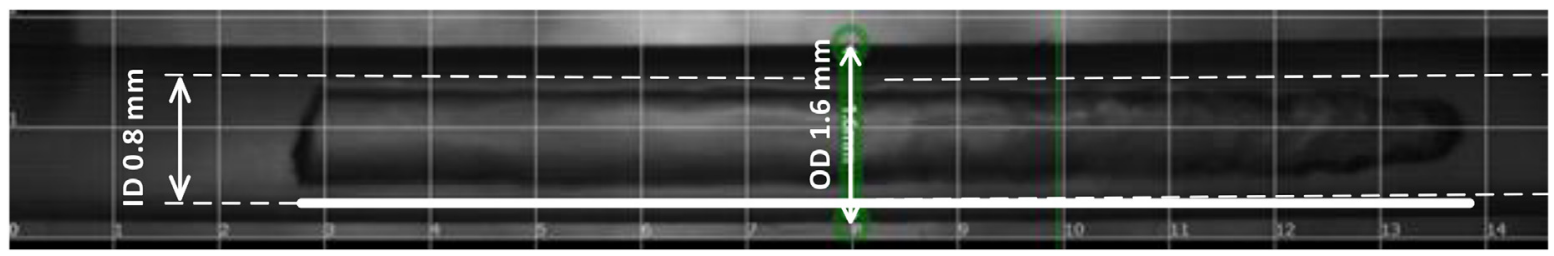

Fig. 6. Slugs expanding downstream $(x=28 \mathrm{~cm})$. 


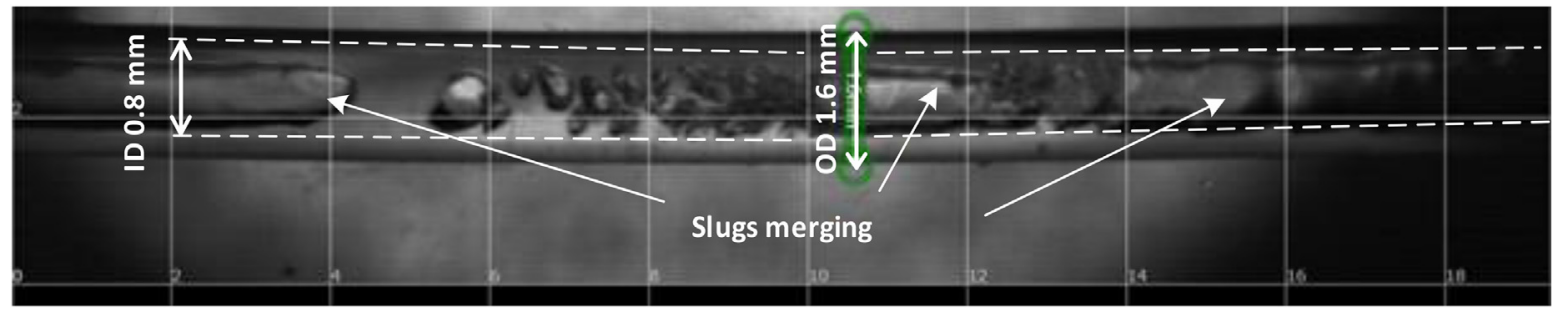

Fig. 7. Slugs from the same bubble burst begin to merge $(x=32 \mathrm{~cm})$.

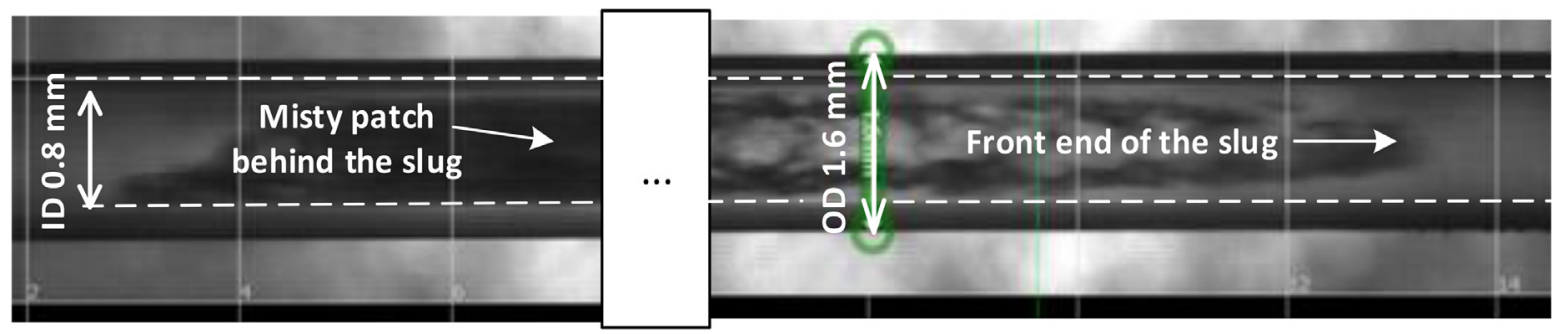

Fig. 8. Misty patches follow the slug $(x=42 \mathrm{~cm})$.

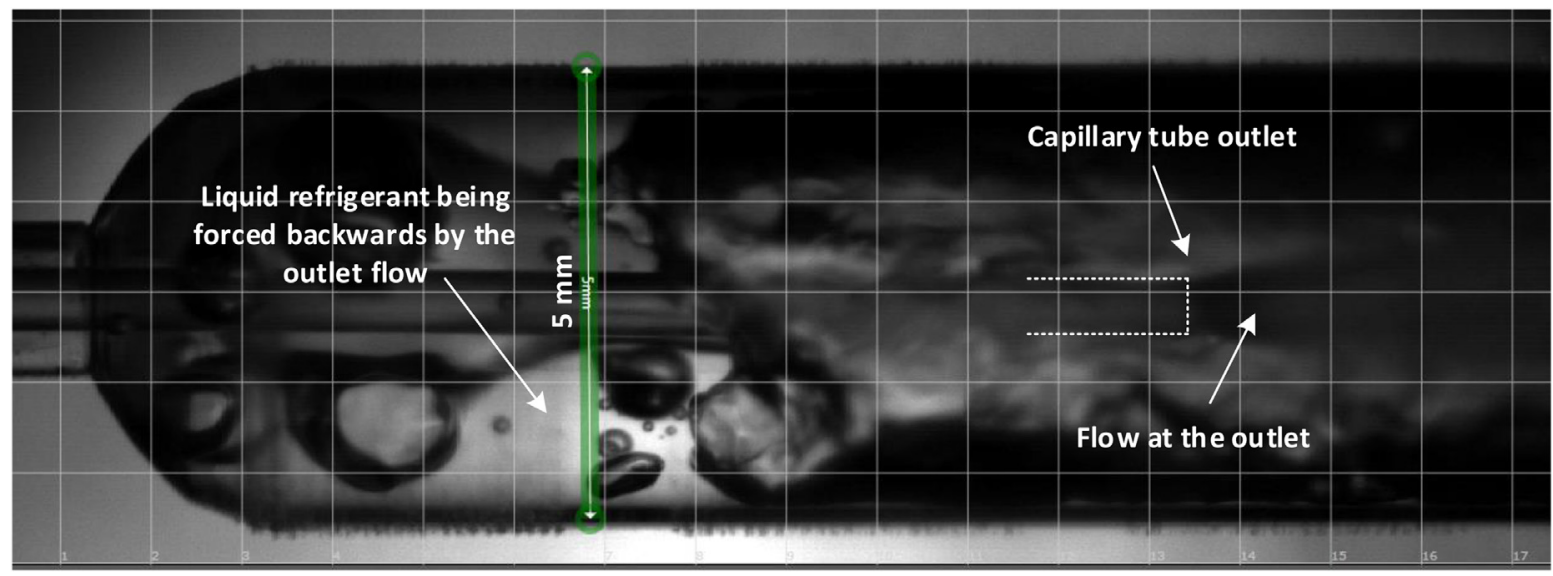

Fig. 9. Refrigerant flow at the capillary tube's outlet.

region however, methods such as particle image velocimetry (PIV) would be needed to determine the velocity of the liquid phase. This would require adding solid particles to the flow without allowing them to clog up the capillary tube and preventing air from breaching the system while adding them. This is without doubt a challenge in itself and is beyond the scope of this work. However, the velocity of the liquid phase can still be estimated to some degree. For example, at the rear end of a bubble or slug. There the liquid and vapor velocities are probably similar, as the overall vapor fraction in a capillary tube is low and it is the liquid that is carrying the bubble or pushing the vapor slug downstream. Although not a perfectly representative value of the liquid velocity, the rear-end velocity of the vapor phase can be clearly determined and no intrusive method is needed. Fig. 10 shows the velocities of the front and rear ends of the vapor phase along the capillary tube's length for the conditions described in Table 3. The x-axis locations were translated into the real positions with respect to the entire length of the capillary tube. The velocity was measured and averaged for three different bubbles/slugs. The vapor phase accelerates downstream from around $3 \mathrm{~m} \mathrm{~s}^{-1}$ at the point of inception up to around $20 \mathrm{~m} \mathrm{~s}^{-1}$ towards the outlet. It is also apparent that the front end of the vapor formation is faster than

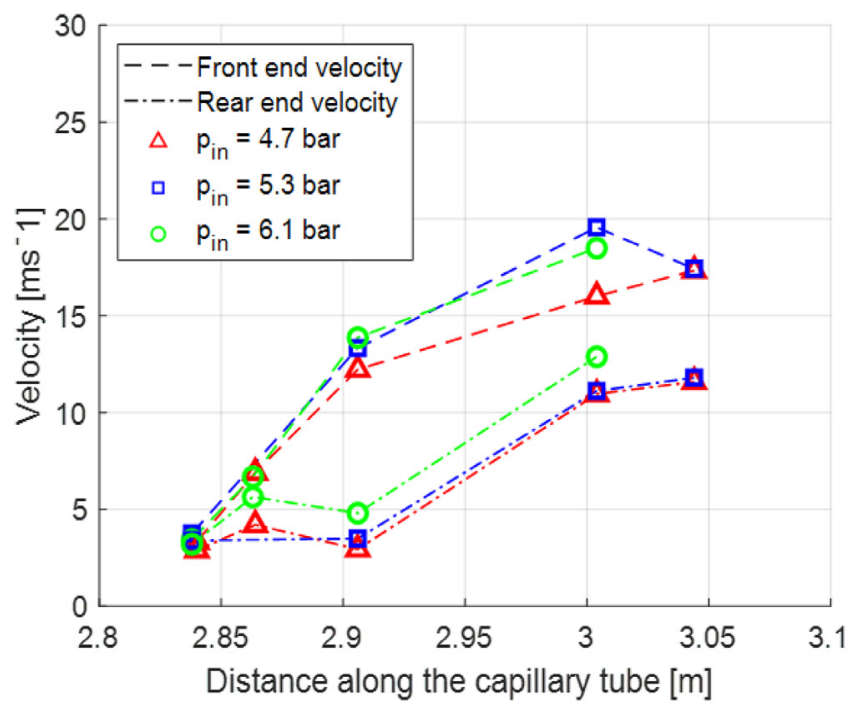

Fig. 10. Velocities of the front and rear ends of the vapor phase along the capillary tube's length. 
Table 3

Flow conditions for experiment shown on Fig. 10.

\begin{tabular}{|c|c|c|c|c|c|c|c|}
\hline $\begin{array}{l}\text { Inlet } \\
\text { pressure } \\
\text { [bar] }\end{array}$ & $\begin{array}{l}\text { Mass flow } \\
\text { rate }\left[\mathrm{kg} \mathrm{h}^{-1}\right]\end{array}$ & $\begin{array}{l}\text { Condensing } \\
\text { temperature }\left[{ }^{\circ} \mathrm{C}\right]\end{array}$ & $\begin{array}{l}\text { Inlet temperature } \\
{\left[{ }^{\circ} \mathrm{C}\right]}\end{array}$ & $\begin{array}{l}\text { Saturation } \\
\text { (flashing) pressure } \\
\text { [bar] }\end{array}$ & $\begin{array}{l}\text { Liquid velocity before } \\
\text { vaporization point }\left[\mathrm{m} \mathrm{s}^{-1}\right]\end{array}$ & $\begin{array}{l}\text { Vapor velocity at } \\
\text { vaporization } \\
\text { point }\left[\mathrm{m} \mathrm{s}^{-1}\right]\end{array}$ & $\begin{array}{l}\text { Reynolds number } \\
\text { before vaporization } \\
\text { point [/] }\end{array}$ \\
\hline 4.7 & 2.2 & 35 & 31.9 & 4.3 & 2.23 & 3.1 & 6880 \\
\hline 5.3 & 2.3 & 40 & 33.5 & 4.5 & 2.37 & 3.3 & 7400 \\
\hline 6.1 & 2.3 & 45 & 41.3 & 5.5 & 2.42 & 3.7 & 8020 \\
\hline
\end{tabular}

its rear end. This confirms our observation that the slugs expand downstream and continue to do so until the outlet.

From the results shown in Fig. 10 it is then possible to obtain the ratio between the front- and rear-end vapor velocities. Again, while that is not an absolutely correct value it is nevertheless an indicator of the velocity slip between the liquid and vapor phases. The front/rear velocity ratio is close to unity only at the point of inception. There the small bubbles are carried by the liquid and the velocities of the two phases are very similar. As the vapor phase expands its velocity begins to exceed the liquid velocity and the ratio increases. Towards the outlet of the capillary tube the vapor phase expands at a slower rate than after the inception and the front/rear velocity ratio decreases. The main conclusion is that the velocity of the vapor phase is not uniform. If the liquid velocity ahead of and behind a vapor slug is more similar to the velocity of the rear end of the slug, then the velocities of the vapor and liquid phases are quite different for most of the two-phase region. In this case, in the authors' opinion, the two-phase flow of refrigerant under the conditions presented is heterogeneous. However, we would like to emphasize that this does not mean that the flow cannot be treated as homogeneous (for example, in numerical or analytical models) and not produce a sufficiently accurate description of the flashing process.

\section{Effect of surface imperfections on two-phase refrigerant flow}

The question now arises as to whether the flow patterns described in the previous sections are representative of what happens in copper capillary tubes that are actually used in vaporcompression refrigeration systems. We described the similarity between the FEP and the copper capillary tube based on a comparison of the inlet and outlet conditions. As the internal diameter and length were equal a similar pressure drop at the same compressor RPM shows that the surface effects of both tubes have a similar overall influence on the refrigerant flow. However, this does not prove that the two-phase flow patterns remain the same as a similar pressure drop could coincidentally be caused by a different type of flow. Consequently, our observation that the flow is not homogeneous might not be true for copper capillary tubes. We wished to create an interval of different surface roughnesses to see if they have an effect on the two-phase flow patterns. The surface roughness of copper capillary tubes depends on the production process and different researchers have reported values from $0.05 \mu \mathrm{m}$ up to $11 \mu \mathrm{m}$ (Meyer and Dunn, 1996). However, a copper capillary tube is considered to have more imperfections than a glass capillary tube (Mikol and Dudley, 1964). By this logic a copper surface might produce more inception points for vapor bubbles and the flow pattern might differ to that in a glass tube. Mikol and Dudley (1964) reported that the inception of vaporization in a glass tube happened at a single point, which is equivalent to what happens in a FEP tube. We therefore assume that the FEP tube has a surface texture and properties that cause a similar evaporation process as in a glass capillary tube. The surface texture of a glass or FEP tube was thus considered the lower limit of our observation interval as there cannot be less than one vaporization point. The upper limit was created by adding imperfections to the internal surface of the FEP capillary tube, thereby increasing the surface roughness. The hypothesis at this point was that if the flow patterns would not change even if the internal tube surface had major surface imperfections then the flow patterns in a copper capillary tube would very likely be similar to those observed in the FEP tube. Two different cases were considered. In the first case several local imperfections were created. In the second case the entire inner surface of the tube was grooved with a sharp spring steel wire. A macroscopic spiral groove was created and the sharp steel tip of the wire created microscopic abrasions on the surface. This enabled us to simultaneously observe both the macroscopic and microscopic influences on two-phase flow.

\subsection{Effect of local imperfections}

In all the experiments where stable evaporating conditions were achieved, i.e., the capillary tube did not draw in vapor at the inlet, the inception of vaporization occurred at the same location, regardless of the inlet pressure or mass flow rate. The vapor bubbles originated from the lower tube wall, around $27 \mathrm{~cm}$ from the capillary tube's outlet. We introduced imperfections in the capillary tube by twisting it and slightly damaging its inner surface every $4 \mathrm{~cm}$ upstream and downstream of the current vaporization point for $8 \mathrm{~cm}$ in each direction (two points in each direction). Our intention was to disturb the metastable flow and force the onset of vaporization. The vaporization point jumped by $4 \mathrm{~cm}$ upstream of the current vaporization point and Fig. 11 shows how the vapor bubbles now form at this imperfection (see Figs. 2-5 for vaporization points in a tube without imperfections).

The earlier onset of vaporization did not have any significant effect on the overall operation of the system in terms of mass flow rate and pressure drop. After the introduction of these imperfections further changes to the inlet conditions did not move the

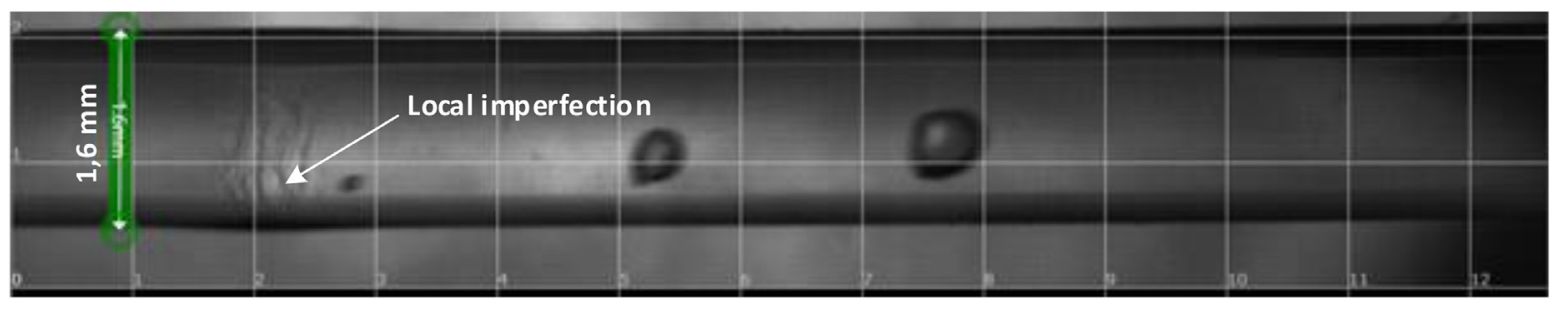

Fig. 11. Inception of vaporization at a surface imperfection. 
starting point of the vaporization. The offset of the vaporization starting point did not affect the flow patterns that were presented in Figs. 5-9.

\subsection{Effect of grooving and abrasions}

In order to observe the effect of an increased surface roughness on the flow patterns, spiral grooves and abrasions were created along the entire length $(1.5 \mathrm{~m})$ of the FEP tube. A non-contact optical profilometer was used to create a 3D profile of the surfaces from which a 2D profile (Fig. 12) could be determined for a representative section of the surface. The profile of the grooved tube in Fig. 12 has an amplitude of around $60 \mu \mathrm{m}$ (the ID of the tube is $800 \mu \mathrm{m}$ ) at intervals of around $250 \mu \mathrm{m}$. The surface of the original tube has no macroscopic profile. The profilometer was unable to measure the profile below the micron level where microscopic abrasions might be visible.

The grooving of the capillary tube resulted in several vaporization points (Fig. 13) scattered randomly around the circumference of the tube (compared to a single point in a smooth tube) when the compressor was operating at $100 \%$ of its nominal RPM. However, when the compressors' RPM were lowered to $60 \%$ of the nominal rate, the vaporization again occurred at only a single point like in Fig. 2-. Because of the limited resolution of the high-speed camera we were not able to determine whether the increase in the number of vapor inception points is due to the microscopic abrasions, the macroscopic grooves, or both.

The refrigerant flow was observed at discrete points along the capillary tube length, as in Figs. 5-9. The downstream evolution of the bubbles is depicted in Fig. 14, which shows different flow patterns established along the capillary tube. The compressors' RPM were set to $60 \%$ of the nominal rate in this case. At $x=29 \mathrm{~cm}$ (Fig. 14 , top) we can see that the flow consists of slugs and smaller bubbles. It seems that either not every bubble can expand into a slug or that more bubbles form downstream from the first vaporinception point. When the flow approaches the outlet, it becomes more homogenous and the vapor and liquid phases are no longer distinguishable from each other to the naked eye. This is shown in Fig. 14 (bottom).

From the results shown in this section we can conclude that a different surface texture has an effect on the flow patterns and the homogeneity of the flow. Therefore, it is not clear whether the results obtained with a FEP capillary tube are representative for copper tubes as well. If the surface texture is smooth and similar to the surface of a FEP capillary tube, then the flow pattern will likely not be homogeneous as it will resemble the flow shown in Figs. 5-9. However, if the surface has many imperfections then it is possible that the flow in a copper capillary tube is more homogeneous due to the many bubbles forming on the entire circumference of the tube, as shown in Figs. 13 and 14. Ideally,

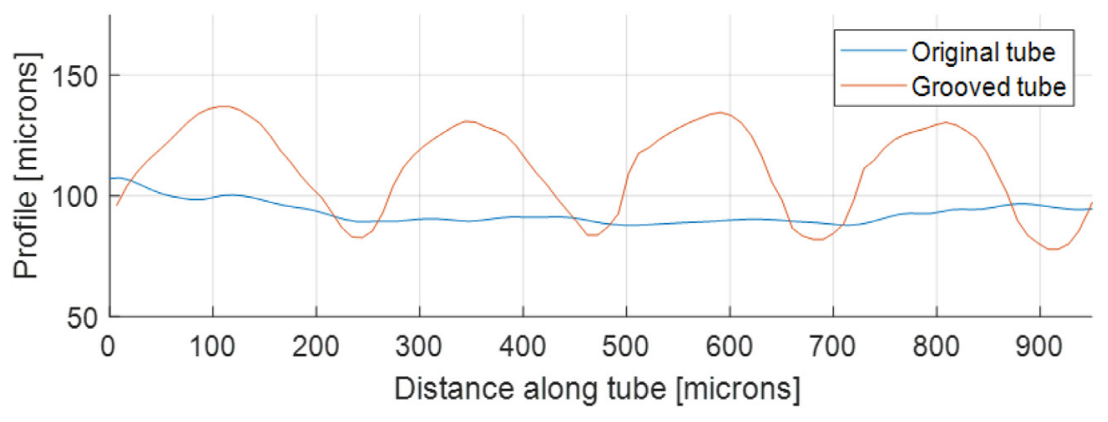

Fig. 12. Surface profiles of samples taken from the original and grooved capillary tubes.

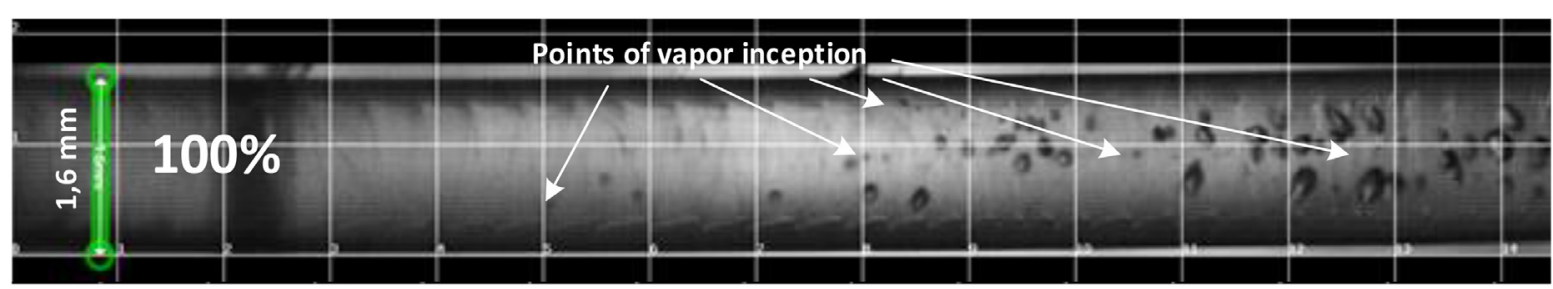

Fig. 13. Inception at $100 \%$ of nominal compressor RPM.

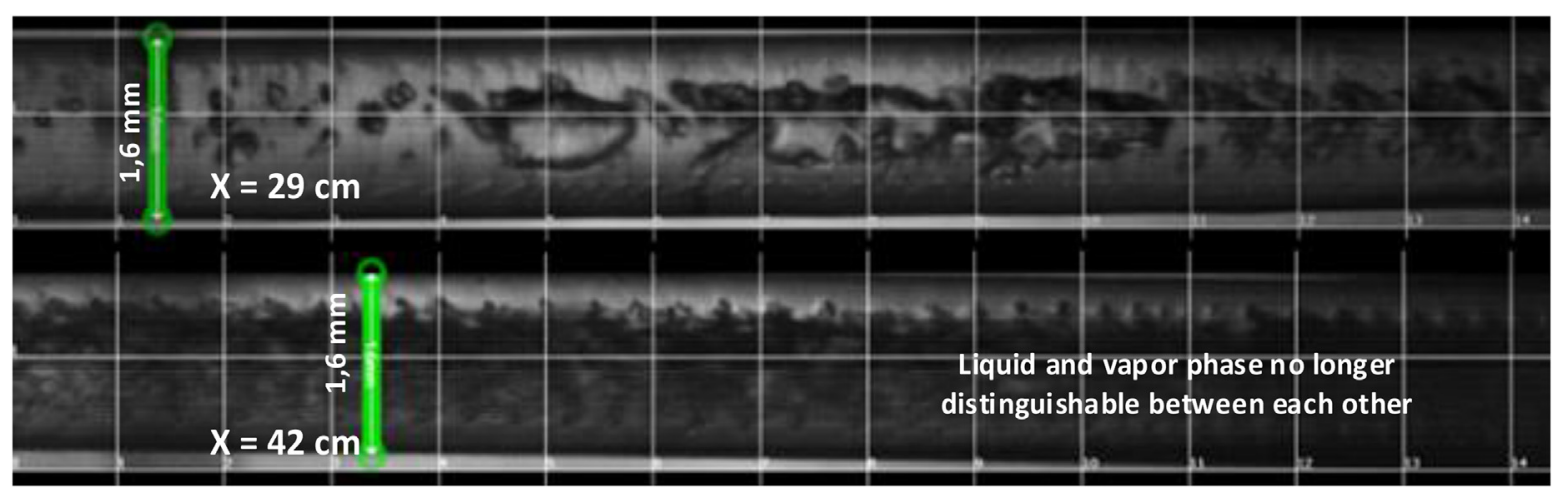

Fig. 14. Top) vapor slugs and bubbles at $x=29 \mathrm{~cm}$, bottom) homogeneous flow at $x=42 \mathrm{~cm}$. The system was operating at $60 \%$ nominal compressor RPM. 
the grooving pattern would have had a smaller amplitude (around $10-20 \mu \mathrm{m})$ as $60 \mu \mathrm{m}$ is substantially larger than the typical roughness of $0.05 \mu \mathrm{m}$ to $11 \mu \mathrm{m}$ given by Meyer and Dunn (1996) for copper capillary tubes. However, due to technical restrictions we did not manage to make a finer grooving. This put us at a disadvantage as our interval of observed surface roughnesses was consequently much larger than the one that could be expected in reality.

\section{Conclusion}

In this article we reported on a visual study of the flow of the refrigerant R600a through a capillary tube made from a FEP polymer. The study showed that different operating conditions such as the liquid velocity and saturation pressure at the point of vapor inception may influence the frequency of the vapor bubble formation and their growth. While traveling downstream, these bursts of bubbles then expanded into slugs and merged with each other into larger slugs, which continued to expand until the outlet of the capillary tube. The two-phase flow in the FEP capillary tube proved to be a predominantly slug flow followed by short misty patches of small bubbles towards the outlet of the tube. By visualizing the refrigerant flow along the entire length of the capillary tube it was possible to determine the velocity of the vapor phase as it continuously accelerated downstream. It was shown that the front end of the vapor phase has a higher velocity than the rear end. The ratio of the vapor phase front- and rear-end velocities exceeded 1.5 throughout most of the two-phase length in the capillary tube and even reached a value of 4 at certain locations. In the author's opinion this indicates that the observed flow of refrigerant in a FEP capillary tube was heterogeneous. An investigation was made to determine whether the results of the study on a FEP capillary tube are representative of the flow in copper capillary tubes. Firstly, a comparison between the FEP capillary tube used in the study and a copper capillary tube was performed and the results showed a minimal difference in terms of the pressure drop $( \pm 3 \%)$ and the mass flow rate $( \pm 5 \%)$ through the tubes. Secondly, because a copper capillary tube is likely to have more imperfections than a FEP capillary tube we studied the effect of different imperfections on the two-phase flow patterns. Two cases were considered. In the first case we were able to discretely move the inception point of the vapor by $4 \mathrm{~cm}$ upstream of the existing point by creating a local imperfection. However, this did not affect the overall operation of the system and did not change the flow pattern. In the second case we created macroscopic grooves and microscopic abrasions on the entire inner surface of the tube. The results showed that the number of vapor-inception points increased and the flow downstream became more homogeneous. Because these surface imperfections have an effect on the inception of vapor bubbles and the homogeneity of the flow we cannot confirm whether the flow patterns found in a FEP capillary tube are representative of the flow in copper capillary tubes as well. Further studies will be necessary to determine whether the surfaces of the FEP and the copper capillary behave in a similar manner during flash evaporation.

\section{Declaration of Competing Interest}

The authors declare that they have no known competing financial interests or personal relationships that could have appeared to influence the work reported in this paper.

\section{Acknowledgments}

This work was financially supported by the Slovenian Research Agency as part of the Young Researcher PhD program.

\section{Supplementary materials}

Supplementary material associated with this article can be found, in the online version, at doi:10.1016/j.ijrefrig.2020.02.030.

\section{References}

Agrawal, N., Bhattacharyya, S., 2007. Adiabatic capillary tube flow of carbon dioxide in a transcritical heat pump cycle. Int. J. Energy Res. 31, 1016-1030. https://doi. org/10.1002/er.1294.

Arora, C.P., 2009. Refrigeration and Air Conditioning, 3rd ed. Tata McGraw-Hill, New Delhi.

Bansal, P.K., Rupasinghe, A.S., 1998. An homogeneous model for adiabatic capillary tubes. Appl. Therm. Eng. 18, 207-219. https://doi.org/10.1016/S1359-4311(97) 00016- 1

Bittle, R.R., Stephenson, W.R., Pate, M.B., 1995. An experimental evaluation of capillary tube-suction line heat exchanger performance with R-152a. ASHRAE Trans. 100 (part 1), 124-135

Bullard, C., Jain, G., 2004. Design and optimization of capillary tube- suction line heat exchangers. In: Proceedings of the International Refrigeration and Air Conditioning Conference. Purdue.

Cooper, L., Chu, C.K., Brisken, W.R., 1957. Simple selection method for capillaries derived from physical flow conditions. Refrig. Eng. 65, 37.

Da Silva, D.L., Ronzoni, A.F., Melo, C., Hermes, C., 2011. A study of transcritical carbon dioxide flow through diabatic capillary tubes. Int. J. Refrig. 34, 834-843. https: //doi.org/10.1016/j.ijrefrig.2011.02.010.

Dirik, E., Inan, C., Tanes, M.Y., 1994. Numerical and experimental studies on adiabatic and nonadiabatic capillary tube with HFC-134a. In: Proceedings of the International Refrigeration Conference at Purdue University. Purdue.

Dubba, S.K., Kumar, R., 2017. Flow of refrigerants through capillary tubes: a state-of-the-art. Exp. Therm. Fluid Sci. 81, 370-381. https://doi.org/10.1016/j. expthermflusci.2016.09.012

Furlong, T.W., Schmidt, D.P., 2012. A comparison of homogenous and separated flow assumptions for adiabatic capillary flow. Appl. Therm. Eng. 48, 186-193. https: //doi.org/10.1016/j.applthermaleng.2012.05.007.

García-Valladares, O., 2007. Numerical simulation and experimental validation of coiled adiabatic capillary tubes. Appl. Therm. Eng. 27, 1062-1071. https://doi. org/10.1016/j.applthermaleng.2006.07.034.

Hartmann, D., Melo, C., 2013. Popping noise in household refrigerators: fundamentals and practical solutions. Appl. Therm. Eng. 51, 40-47. https://doi.org/10.1016/ j.applthermaleng.2012.08.054.

Heimel, M., Lang, W., Berger, E., Almbauer, R., 2012. A homogenous capillary tube model - Comprehensive parameter studies using R600a. In: Proceedings of the International Refrigeration and Air Conditioning Conference. Purdue.

Khan, M.K., Kumar, R., Sahoo, P.K., 2009. Flow characteristics of refrigerants flowing through capillary tubes - A review. Appl. Therm. Eng. 29, 1426-1439. https:// doi.org/10.1016/j.applthermaleng.2008.08.020.

Koizumi, H., Yokoyama, K., 1980. Characteristics of refrigerant flow in a capillary tube. ASHRAE Trans. 86, 19-27. https://doi.org/10.1016/0029-5493(93) 90092-N.

Li, R.-.Y., Lin, S., Chen, Z.-.Y., Chen, Z.-.H., 1990. Metastable flow of R12 through capillary tubes. Int. J. Refrig. 13, 181-186. https://doi.org/10.1016/0140-7007(90) 90073-6.

Lin, S., Kwok, C.C.K., Li, R.Y., Chen, Z.H., Chen, Z.Y., 1991. Local frictional pressure drop during vaporization of R-12 through capillary tubes. Int. J. Multiph. Flow 17. 95-102. https://doi.org/10.1016/0301-9322(91)90072-B.

Marcinichen, J.B., Melo, C., 2006. Comparative analysis between a capillary tube and an electronic expansion valve in a household refrigerator. In: Proceedings of the International Refrigeration and Air Conditioning Conference. Purdue.

Martínez-Ballester, S., Bardoulet, L., Pisano, A., Corberán, J.M., 2017. Visualization of refrigerant flow at the capillary tube inlet of a high-efficiency household refrigerator. Int. J. Refrig. 73, 200-208. https://doi.org/10.1016/j.ijrefrig.2016.09.019.

Melo, C., Ferreira, R.T.S., Boabaid Neto, C., Goncalves, J.M., Mezavila, M.M., 1999. An experimental analysis of adiabatic capillary tubes. Appl. Therm. Eng. 19, 669684. https://doi.org/10.1016/S1359-4311(98)00062-3.

Melo, C., Torquato Vieira, L.A., Pereira, R., 2002. Non-adiabatic capillary tube flow with isobutane. App. Therm. Eng. 22, 1661-1672. https://doi.org/10.1016/ S1359-4311(02)00072-8.

Meyer, J.J., Dunn, W.E., 1996. Alternative refrigerants in adiabatic capillary tubes. In: Technical report. Urbana.

Mikol, E.P., Dudley, J.C., 1964. A visual and photographic study of the inception of vaporization in adiabatic flow. J. Fluids Eng. Trans. ASME 86, 257-261. https: //doi.org/10.1115/1.3653052.

Motta, S.F.Y., Parise, J.A.R., Braga, S.L., 2002. A visual study of R-404A/oil flow through adiabatic capillary tubes. Int. J. Refrig. 25, 586-596. https://doi.org/10. 1016/S0140-7007(01)00057-3.

Pascua, P.F., 1953. Metastable flow of Freon-12. Refrig. Eng. 61, 1084-1088.

Pate, M.B., Tree, D.R., 1984. An analysis of pressure and tempearture measurements along a capillary tube-suction line heat exchanger. ASHRAE Trans. 90 (part 2), 291-301.

Sahlin, E., 2002. Capillary zone electrophoresis in laboratory-made fluorinated ethylene propylene capillaries. J. Chromatogr. A 972, 283-287.

Sami, S.M., Maltais, H., 2000. Numerical modeling of alternative refrigerants to HCFC-22 through capillary tubes. Int. J. Energy Res. 24, 1359-1371. 
Schulz, U.W., 1985. State of the art: the capillary tube for, and in, vapor compression systems. ASHRAE Trans. 91, 92-103.

Seixlack, A.L., 1996. Modeling the HFC 134a flow through capillary tubes using a two-fluid model. In: Proceedings of the International Refrigeration and Air Conditioning Conference. Purdue.

Seixlack, A.L., Barbazelli, M.R., 2009. Numerical analysis of refrigerant flow along non-adiabatic capillary tubes using a two-fluid model. Appl. Therm. Eng. 29, 523-531. https://doi.org/10.1016/j.applthermaleng.2008.03.012.

Tannert, T., Hesse, U., 2016. Noise effects in capillary tubes caused by refrigerant flow. In: Proceedings of the International Refrigeration and Air Conditioning Conference. Purdue.

Taylor, G.I., 1960. The rear meniscus of a long bubble steadily displacing a Newtonian liquid in a capillary tube. J. Fluid Mech. 10, 161-165.

Vinš, V., Hrubý, J., Vacek, V., 2010. Numerical simulation of gas-contaminated refrigerant two-phase flow through adiabatic capillary tubes. Int. J. Heat Mass Transf. 53, 5430-5439. https://doi.org/10.1016/j.ijheatmasstransfer.2010.07.013.
Wang, J., Cao, F., Wang, Z., Zhao, Y., Li, L., 2012. Numerical simulation of coiled adiabatic capillary tubes in $\mathrm{CO} 2$ transcritical systems with separated flow model including metastable flow. Int. J. Refrig. 35, 2188-2198. https://doi.org/10.1016/j. ijrefrig.2012.07.012.

Weisman, J., 1983. Two-phase flow patterns. Handbook of Fluids in Motion. Ann Arbor Science Publishers, Ann Arbor.

Wong, T.N., Ooi, K.T., 1996. Adiabatic capillary tube expansion devices: a comparison of the homogeneous flow and the separated flow models. Appl. Therm. Eng. 16, 625-634. https://doi.org/10.1016/1359-4311(95)00061-5.

Wongwises, S., Pirompak, W., 2001. Flow characteristics of pure refrigerants and refrigerant mixtures in adiabatic capillary tubes. Appl. Therm. Eng. 21, 845-861. https://doi.org/10.1016/S1359-4311(00)00090-9.

Xu, B., Bansal, P., 2002. Non-adiabatic capillary tube flow: a homogeneous mode and process description. Appl. Therm. Eng. 22, 1801-1819. https://doi.org/10. 1016/S1359-4311(02)00110-2. 